\section{COPD at work: exposures are different than in the past, but still matter}

\author{
Dick Heederik, ${ }^{1}$ David M Mannino 2,3
}

This present common knowledge about the role of occupational exposures in the development of COPD has not been without controversy and is generally accepted only for less than two decades. ${ }^{1}$ This is because the dominant cause of COPD in high-income countries is cigarette smoking. Despite the biological plausibility of other inhaled agents being causally implicated, only the role of tobacco smoke was accepted as a cause of COPD in the mid-1980s. ${ }^{2}$ At that time, chronic non-malignant lung disease characterised by airflow limitation became more common in occupational population studies as the incidence of TB and pneumoconiosis were decreasing in major heavy industries (mining, foundries). But it was not commonly accepted that occupational dust and fumes exposures could be a cause of this group of diseases, the reasons being that obstructive respiratory disease are multifactorial diseases, strongly associated to non-occupational factors. As a result, a heated discussion existed at that time in the literature on the role of occupational exposures in relation to what we now refer to as COPD. In the case of coal workers, perhaps the best studied occupational group at that time, some argued that airflow limitations were of minor degree and not sufficient to impair lung function and disable the worker unless he was a smoker as well. ${ }^{4-6}$ Others disagreed and argued that clinically relevant decreased in lung function could result from a lifetime exposure to coalmine dust. ${ }^{23}$ Some suggested that the lung function declines from coal dust exposure could be of the same magnitude as those resulting from cigarette smoking. ${ }^{7-9}$

In the 1980s, several other factors were believed to contribute to the controversies on the relationship between occupational exposures and COPD. For instance, the absence of longitudinal studies, focus

\footnotetext{
${ }^{1}$ Institute for Risk Assessment Sciences, Division of Environmental Epidemiology, University of Utrecht, Utrecht, The Netherlands

${ }^{2}$ Department of Medicine, University of Kentucky College of Medicine, Lexington, Kentucky, USA ${ }^{3}$ Medical Affairs, GlaxoSmithKline, Philadelphia, Pennsylvania, USA
}

Correspondence to Dr Dick Heederik, Institute for Risk Assessment Sciences, Division of Environmental Epidemiology, University of Utrecht, Utrecht NL-3508 TD, The Netherlands; d.heederik@uu.nl on work-force based studies, the paucity of statistical and epidemiological techniques to adjust for smoking and other confounders and the presence of other lung diseases (TB, pneumoconiosis) have complicated our understanding of the relationship between occupational exposures and COPD. ${ }^{10}$ The emergence of open population studies, which were believed to be less sensitive to the healthy worker effects, and availability of longitudinal studies improved our understanding about the role of occupational exposures. ${ }^{1}$ An important factor since the 1980s was the initiation of several general population studies. Initially these studies focused on differences between 'blue-collar' and 'white-collar' workers or simple categorisations of job titles by the presence of an occupational dust, fumes or gaseous exposure. Later, exposure assessment became more sophisticated by using job exposure matrices. The European Community Respiratory Health Survey is an enormous research effort combining data from different countries which have been collected using a shared protocol. The paper by Lytras et al is a product from this work and describes results of the analysis of 20 years of follow-up in a population comprising $>3300$ individuals studied in 24 centres across 12 European countries. ${ }^{11}$ COPD incidence was defined physiologically in this study. The authors used postbronchodilator lung function tests based on the lower limit of normal and resulted in 1.4 cases per 1000 personyears of follow-up. COPD incidence was associated to occupational exposures at baseline and during follow-up using a Job Exposure Matrix. COPD incidence was statistically significantly associated with exposure to biological dusts, gases and fumes and pesticides. The authors used a very conservative analytic approach, excluding subjects who were obstructed at baseline based on pre-bronchodilator spirometry, excluding subjects with asthma at baseline, and classifying subjects based on post-bronchodilator spirometry at follow-up. This resulted in $89 / 3343$ $(2.7 \%)$ of subjects developing COPD during follow-up. Using a more inclusive approach (not excluding subjects with baseline asthma and using pre-bronchodilator lung function to classify subjects at follow-up) more than doubled the period incidence of COPD to $5.8 \%(318 / 3776$, supplemental table 10). This more sensitive approach, however, diminished the ability to determine the effects of the various occupational exposures.

The overall attributable risk was 20\%. Thus, results suggest that without these occupational exposures, 20\% of COPD cases would not have occurred. The population-attributable fraction of occupational factors to the burden of COPD morbidity has been estimated to range between $15 \%$ and $20 \%$ and may reach a value of $40 \%$ among non-smokers. ${ }^{12}$ Thus, this study is consistent with previous estimates. In Europe, a total of 39300 deaths have been estimated for the year 2000, using previously mentioned attributable risks, where inhaled occupational exposures such as dusts and fumes were thought to have made a material contribution. $^{13}$

One should be cautious with the interpretation of these associations. The different occupational exposures sometimes correlate strongly, and the study is too small to be certain that associations are the results of one unique occupational exposure. As an example, for pesticides, a distinction was made between herbicides, insecticides and fungicides. However, correlations between these three exposure categories were relatively high and associations between these three categories and COPD incidence had very similar point estimates so that no meaningful inferences can be made from this subanalysis. Despite this disclaimer, the authors found that biological dusts were strongest associated with COPD incidence and had the highest population-attributable risk of $10.5 \%$. The attributable risk of exposure to gases and fumes was slightly lower (9.2\%) and the lowest for pesticides (4.4\%). Unfortunately, biological agents were not further distinguished into different aetiological categories (organic dust, (endo)toxins and allergens) and job titles involved in biological exposure were not given, so it remains unclear which biological exposures are specifically involved. Although the observation that biological agents might be associated with COPD incidence is not new, little information is available on COPD and biological dusts and the job titles which were involved in exposure to biological dusts. Endotoxin is known to cause emphysema in animal models. ${ }^{14} \mathrm{~A}$ few biological dusts, such as endotoxins, have been associated explicitly with accelerated lung function decline in cotton workers and 
livestock farmers, ${ }^{15-17}$ but it remains controversial whether this accelerated decline is indicative of COPD on other respiratory phenotypes such as non-allergic asthma. ${ }^{18}$ Pesticides have been associated with respiratory disease, in particular with asthma. In the US Agricultural Health study, pesticide exposure has been associated with chronic bronchitis symptoms, also in non-smoking women. ${ }^{19} 20$ Unfortunately, lung function data are not available for this large farming population survey. Thus, this finding is not easily interpreted against the background of the evidence available in the literature.

Findings in this European Community Respiratory Health Survey (ECHRS) paper require follow-up and a more in-depth evaluation. Replication by independent studies is warranted. An observation that is also important, and complicates future studies, is that occupational exposures occur in a more diffuse way than in the past when they occurred in some of the large basic industries with large populations at risk. Now, the exposed population at risk is often involved in service industries with different processes and exposure is not always clearly determined by the job title anymore. This requires more refined approaches for exposure assessment.

Contributors Both authors have contributed to the writing and editing of this editorial.

Funding The authors have not declared a specific grant for this research from any funding agency in the public, commercial or not-for-profit sectors.
Competing interests DMM is an employee and shareholder of GlaxoSmithKline. DH has no competing interest to declare.

Patient consent Not required.

Provenance and peer review Commissioned; externally peer reviewed.

(C) Article author(s) (or their employer(s) unless otherwise stated in the text of the article) 2018. All rights reserved. No commercial use is permitted unless otherwise expressly granted.

\section{Check for updates}

To cite Heederik D, Mannino DM. Thorax 2018;73:997-998.

Accepted 4 June 2018

Published Online First 19 June 2018

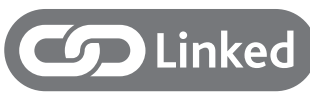

http://dx.doi.org/10.1136/thoraxjnl-2017-211158

Thorax 2018;73:997-998.

doi:10.1136/thoraxjnl-2018-211661

\section{REFERENCES}

1 Balmes J, Becklake M, Blanc P, et al. American Thoracic Society Statement: Occupational contribution to the burden of airway disease. Am I Respir Crit Care Med 2003;167:787-97.

2 Becklake MR. Chronic airflow limitation: its relationship to work in dusty occupations. Chest 1985;88:608-17.

3 Becklake MR. Occupational exposures: evidence for a causal association with chronic obstructive pulmonary disease. Am Rev Respir Dis 1989:140:585-91.

4 Occupation and bronchitis. Lancet. 1980;1:235-6.

5 Abrams HK. Aggravation of lung disease. Scand J Work Environ Health 1984;10:487-93.

6 Morgan WK, dust 0. disability, and death. Am Rev Respir Dis 1986;134:639-41.
7 Elmes PC. Relative importance of cigarette smoking in occupational lung disease. $\mathrm{Br} J$ Ind $\mathrm{Med}$ 1981;38:1-13.

8 Seaton A. Coal and the lung. Thorax 1983;38:241-3.

9 Marine WM, Gurr D, Jacobsen M. Clinically important respiratory effects of dust exposure and smoking in British coal miners. Am Rev Respir Dis 1988;137:106-12.

10 Simpson CR, Hippisley-Cox J, Sheikh A. Trends in the epidemiology of chronic obstructive pulmonary disease in England: a national study of 51804 patients. Br J Gen Pract 2010;60:277-84.

11 Lytras T, Kogevinas M, Kromhout H, et al. Occupational exposures and 20-year incidence of COPD: the European Community Respiratory Health Survey. Thorax 2018;73:1008-15.

12 Occupation BPD. and COPD: a brief review. J Asthma 2012;49:2-4.

13 Driscoll T, Nelson DI, Steenland K, et al. The global burden of non-malignant respiratory disease due to occupational airborne exposures. Am J Ind Med 2005:48:432-45.

14 Shapiro SD. Animal models for COPD. Chest 2000;117:223S-7.

15 Vogelzang PF, van der Gulden JW, Folgering H, et al. Longitudinal changes in bronchial responsiveness associated with swine confinement dust exposure. Chest 2000;117:1488-95.

16 Vogelzang PF, van der Gulden JW, Folgering $\mathrm{H}$, et al. Endotoxin exposure as a major determinant of lung function decline in pig farmers. Am J Respir Crit Care Med 1998;157:15-18.

17 Wang XR, Zhang HX, Sun BX, et al. A 20-year followup study on chronic respiratory effects of exposure to cotton dust. Eur Respir J 2005:26:881-6.

18 Eduard W, Douwes J, Omenaas E, et al. Do farming exposures cause or prevent asthma? Results from a study of adult Norwegian farmers. Thorax 2004;59:381-6.

19 Hoppin JA, Valcin M, Henneberger PK, et al. Pesticide use and chronic bronchitis among farmers in the Agricultural Health Study. Am J Ind Med 2007:50:969-79.

20 Valcin M, Henneberger PK, Kullman GJ, et al. Chronic bronchitis among nonsmoking farm women in the agricultural health study. J Occup Environ Med 2007;49:574-83. 